\title{
Principal Management Skills, School Admin Support and Teacher's Professional Development: Basis for Intervention
}

\author{
Razhierda Alvarez-Mummuh, LPT, MAHE \\ razhierdamummuh@gmail.com \\ MEQ 13 MBAA Apartment Cabatangan, Zamboanga City 700, Philippines
}

\begin{abstract}
This study aimed to determine the significant relationship between the principal management skills to the teachers' professional development. It utilizes teachers as a respondent of this study. The study is a descriptive quantitative research study which was appropriate to respond on the stated problems using four-point likert scale research instrument as a medium for data collection and analysis. The findings revealed that, the null hypothesis of no significant relationship of the principal management skills and teachers' professional development was rejected. It implies that, there was an association between the management skills demonstrated by principal to the progression of teachers' professional development lead into conclusion that, principal's management skills could be the factor as an impact for teachers' professional development.
\end{abstract}

Keywords: management skill; support; professional development;education

\section{Introduction}

School principals are some of the most important leaders in the school as they shape the education of our children. A principal is in charge of a large team of staff, as well as a huge number of students and they are the mediator between students, teachers, and their parents.

The principal management skills are the ability to adapt and innovate. They have to lead by example and must not be afraid of change but rather make changes to the curriculum and teaching style as these new trends and techniques emerge. A good and effective principal adapt the following skills: leadership, IT, communication skills and have the ability to delegate a task to someone capable of handling it. They must be decisive by giving impressions right there and then to solved and closed the issue quickly. Possess problemsolving skills since principal faces a variety of problems from the school, teachers and into the students' issues to solve.

School administrators work in schools, but not as teachers. They are accountable for overseeing the administrative duties at schools from preschool through post-graduate levels. An educational administrator ensures a safe and productive learning environment for the students and faculty at their institution. Budgets, logistics, schedules, disciplinary actions, evaluations, and public relations fall under the purview of educational administrators. School administrators provide leadership and lay out optimistic goals and visions for the institutions they serve.

Teachers' performance demonstrated impact on students' learning as established through student achievement test scores, observed pedagogical practices, or employer or student surveys. Teacher play the most important role in education system of enhancing student learning that matter to their future success. Teacher performance has a direct influence on student learning and student progress is the standard by which teacher performance should be assessed (Barbara C.Hunt, 2009). 


\section{Statement of the Problem}

This study aimed to determine the principal management skills and the school administrator support in the teachers need for professional development of Don Pablo Lorenzo Memorial High School Stand-Alone Senior High School. Specifically, the study aims to find out:

1. What is the level of principal management skills?
a. Empower others
b. Motivate change
c. Educator first/administrator second

2. What is the level of school administrative officer support?

3. What is the level of teacher's professional development?

4. Is there a significant relationship between the principal's management skills and school administrative officer support?

5. Is there a significant relationship between the school principal management skills and teachers' professional development?

\section{Scope of the Study}

This study focuses on the relationship of the principal management skills and school administrative officer's support to the teacher's professional development which will be the basis for the school performance. The respondents of this study are the proficient level teachers of DPLMHS-SHS Senior High School - Stand Alone for this academic year 2021-2022. The outcome of this study will serve as a basis for schools' intervention program after finding the result.

\section{Research Design}

The study utilized the descriptive quantitative type of research employing survey method. Descriptive research is appropriate to determine the level of principals' management skills, school administrative support, and, teachers' professional development. It is quantitative - correlational study because it is considered as the most appropriate to determine the relationship between the principal management skills, school administrative support and teachers' professional development. This used a comparative study which is appropriate to determine the significant difference of the principal's management skills when responses grouped according to their demographic profile.

\section{Population and Sampling Technique}

The target populations of the study were senior high school teachers and school administrators who are assigned to teach in the mentioned school. The researcher based the teacher's performance from the teacher's professional development attended. The respondents were grouped according to their subject taught and field of specialization graduated and with trainings this will be done based from the assignment order and designation order. 


\section{Research Instrument}

There is only one research instrument to be used in this study. The researcher gathered the documents that are needed for this study. The researcher gathered data on the teacher's performance taken from the assessment of the students handled by them. Ask at least 3 students from the class to answer a simple survey on the performance of their teacher, of the mentioned senior high schools' teachers. Moreover, this study utilizes researchers' made survey questionnaire which entails two parts. Part I. entails the respondents' demographic profile, where, teachers have to fill-in their name (as optional), length of service, gender, educational attainment, and length of service. PART II. It entails the statement regarding on principal's management skills, school administrative support. Provided with 4-point Likert scale which indicates each point as the "strongly agree, agree, disagree, strongly disagree" that manifest respondents" perception and observation regarding on the variable given.

\section{Ethical Consideration}

This study ensured the ethical consideration upon distribution and collecting of research instrument, as well as, its statistical and data analysis and interpretation. The study observed ethical practices in terms of the choice of sampling technique in order to ensure that, all population of the mentioned school are given equal opportunity to be the respondent of this study. The researcher ensured that, there is no bias practices in the selection of samples as a representative to respond on this study. It ensured that, the respondents' demographic profile kept to the utmost confidentiality for a data privacy. The study ensured that, there is no violation committed by researcher upon data collection and respondents' involvement for this study. It ensured also that, COVID 19 safety protocols are strictly practiced. The responses were carefully treated using the appropriate statistical tool treatment to generate the result that anchors to the stated problems.

\section{Data Gathering Procedure}

The researcher will secure a permission from the School Division Superintendent to allow her to conduct a study in selected schools. The researcher will ask permission from the School Heads or principals to allow her to gather data. After approval, the researcher explained the purpose of the conduct of the said study to the randomly selected teachers' respondents. Then the researcher gathered the data such as IPCRF rating may use, the answers of the selected students and the experience of the teacher respondents. After all the data had been gathered and collected, the researcher tallied the data. Upon compiling, the raw data were input in the Excel/Spreadsheet and SPSS software and were analyzed and interpreted.

\section{Data Analysis}

Table 1 - Principal Management Skills

\begin{tabular}{lccc} 
& \multicolumn{1}{c}{ Principal Management Skills } & Mean & Description \\
\hline Empower Others & 3.59 & Highly Skilled \\
\hline Motivate Change & 3.60 & Highly Skilled \\
\hline Educator First/Administrator Second & 3.69 & Highly Skilled \\
\hline GRAND MEAN & $\mathbf{3 . 6 3}$ & Highly Skilled \\
\hline
\end{tabular}

Legend: $1.00-1.75=$ Strongly Disagree; $1.76-2.50=$ Disagree; $2.51-3.25=$ Agree; $3.26-4.00=$ Strongly Agree 
The table 1 shown that, all statements concerning on the principal management skills got the computed mean 3.59-3.69 which indicates as "Highly Skilled" which implied that the school head of the stand-alone senior high school performed satisfactorily based on the responses of all the teachers in the said school. This could also imply that, respondents or teachers viewed that, their principal's management skills performed highly satisfied that manifests in empowering others, motivate for change and educator first/administrator second that anchors to the teachers' expectations that served as an impact for teachers' quality of work influenced by the principal's management skills.

Particularly, the principal empowered teachers by providing them the opportunity to participate in curriculum development and design with regards to the management skills which gathered $\mathrm{x}=1.38$ this showed that the teachers were satisfied enough on the management skills of the school head which provided them to be empowered. Teachers were empowered as well, by giving them the following opportunities to be empowered; help in the process of decision making on school policy this was interpreted in the data that garnered $\mathrm{x}=1.36$. Helps to come up a strategy, vision, and mission with the planning team with a computed mean of $\mathrm{x}=1.42, \mathrm{x}=1.28$ for providing the help to support their initiatives and ideas for professional development. Provides encouragement to set out personal goals in attending conferences and help in funding it earned $\mathrm{x}=1.32$. Provides support to a mentoring program to be facilitated by the teachers with the new colleagues $\mathrm{x}=1.38$. Helps in making the school inclusive to all teachers by providing education on equity and diversity $\mathrm{x}=1.26$. Provides a collaborative environment and team building $\mathrm{x}=1.30$. Provides emphasis on communication to build a school culture $\mathrm{x}=1.40$. Provides opportunity to thank teachers for what they do in and out of the classroom to show appreciation of their work $\mathrm{x}=1.28$. The computed mean garnered for each of the statement showed the satisfaction of all the teachers in the management skills of the school principal.

Similarly, the table 3 showed that the teachers were motivated by the good leadership possessed by the school head and the following computed means justified their satisfaction on the management skills of the principal. Practiced time management abilities $\mathrm{x}=1.34$. With great interpersonal skills $\mathrm{x}=1.24$. Being organized in all activities $\mathrm{x}=1.30$. Provide effective communication skills $\mathrm{x}=1.36$. Firm in a decision making and not a changeable mind 1.38. Provide fair treatment and not favoritism $\mathrm{x}=1.40$. Provide technical assistance in terms of technology $\mathrm{x}=1.40$. Approachable and open to accept suggestion $\mathrm{x}=1.26$. Lead teachers and staff as a role model 1.38. Praise mistakes for encouragement $\mathrm{x}=1.36$.

Also, as part of a good principal management skills teachers were empowered and these showed in the computed mean that the administrators skilled in the following: Teachers accomplish what is needed in the classroom $x=1.32$. Supported with the available tools and resources for instruction $x=1.40$. Preparation to ensure teachers and students appropriately utilize tools and resources $\mathrm{x}=1.46$. Create a climate hospitable to education $x=1.36$. Cultivating leadership in others 1.48. Support PTA programs 1.44. Teachers accomplish what is needed in the classroom $\mathrm{x}=1.46$. Supported with the available tools and resources for instruction $\mathrm{x}=$ 1.48. Preparation to ensure teachers and students appropriately utilize tools and resources $x=1.42$. Create a climate hospitable to education $\mathrm{x}=1.50$. 
Table 2 - School Administrator Support

\begin{tabular}{|c|c|c|c|}
\hline No. & STATEMENT & MEAN & DESCRIPTION \\
\hline \multicolumn{4}{|c|}{ School admin support possess... } \\
\hline 1 & Encourage and support team work. & 3.66 & Highly Supported \\
\hline 2 & Provide mindsets on thinking creativity and passion for learning. & 3.66 & Highly Supported \\
\hline 3 & Give positive feedbacks for a job well done. & 3.76 & Highly Supported \\
\hline 4 & Build relationships to incur trust. & 3.90 & Highly Supported \\
\hline 5 & Provide opportunities to attend professional development. & 3.88 & Highly Supported \\
\hline 6 & Model good coaching behavior. & 3.78 & Highly Supported \\
\hline 7 & Provide team building activities for camaraderie in the workplace. & 3.86 & Highly Supported \\
\hline 8 & Provide transparency report on school funds allocations. & 3.84 & Highly Supported \\
\hline 9 & Provide materials/supplies for instructions. & 3.82 & Highly Supported \\
\hline 10 & Prioritize teachers' welfare among others. & 3.82 & Highly Supported \\
\hline \multicolumn{2}{|c|}{ GRAND MEAN } & 3.79 & HIGHLY SUPPORTED \\
\hline
\end{tabular}

The table 2 illustrated that, the statements regarding school administrative officer support in terms of admin support possessed teachers' satisfaction by the computed mean which ranges from 3.66-3.82 and this signified the findings of "Highly Supported". Admin support statements gathered the following computed mean which implies that, school administrators satisfactorily rendered in encouraging and supporting team work and Provide mindsets on thinking creativity and passion for learning have the same mean of $\mathrm{x}=1.40$. Give positive feedbacks for a job well done $\mathrm{x}=50$. Build relationships to incur trust $\mathrm{x}=1.64$. Provide opportunities to attend professional development $\mathrm{x} 1.62$. Model good coaching behavior $\mathrm{x}=1.52$. Provide team building activities for camaraderie in the workplace $\mathrm{x}=1.60$. Provide transparency report on school funds allocations $x=1.58$. Provide materials/supplies for instructions and Prioritize teachers' welfare among others and $\mathrm{x}=1.56$. all of those responses coming from the teachers anchors to their expectations towards school administration support in which, the administrators provide the quality of their service suited to the teachers' demands.

Table 3 - Teacher's Professional Development

\begin{tabular}{|c|c|c|c|}
\hline No. & STATEMENT & MEAN & DESCRIPTION \\
\hline \multicolumn{4}{|c|}{ Supports encourage... } \\
\hline 1 & Help to seek opportunities for enhancement training. & 3.68 & Highly Developed \\
\hline 2 & $\begin{array}{l}\text { Provide balance distribution of teaching loads to give time for teachers' } \\
\text { academic studies. }\end{array}$ & 3.66 & Highly Developed \\
\hline 3 & $\begin{array}{l}\text { Fair-minded in assigning teachers to attend seminars, trainings and the } \\
\text { like. }\end{array}$ & 3.66 & Highly Developed \\
\hline 4 & $\begin{array}{l}\text { Provide school financial support for enhancement trainings outside the } \\
\text { city. }\end{array}$ & 3.52 & Highly Developed \\
\hline 5 & $\begin{array}{l}\text { Provide service credit for enhancement trainings attended beyond } \\
\text { official time. }\end{array}$ & 3.48 & Highly Developed \\
\hline 6 & Provide flexible time for submitting reports while on schooling. & 3.56 & Highly Developed \\
\hline 7 & Provide clear guidance and career development advice. & 3.54 & Highly Developed \\
\hline 8 & $\begin{array}{l}\text { Recognize the value of motivation to support teachers' professional } \\
\text { development. }\end{array}$ & 3.54 & Highly Developed \\
\hline 9 & $\begin{array}{l}\text { Allow teachers to attend trainings related to their field of } \\
\text { specialization. }\end{array}$ & 3.68 & Highly Developed \\
\hline 10 & Recognize professional growth in the recommendation for promotion. & 3.54 & Highly Developed \\
\hline GRA & D MEAN & 3.58 & HIGHLY DEVELOPED \\
\hline
\end{tabular}


The table 3 represented the teacher's professional development where the computed mean collected ranges from 3.52-3.68 which signified "Highly Developed". Majority of the teachers are benefited with the professional development addressed by their principal along with their management. Based from the findings the teachers were satisfied on the encouragement provided and the statements earned the following mean. Encourage and support team work $\mathrm{x}=1.32$, Provide mindsets on thinking creativity and passion for learning and give positive feedbacks for a job well done. $\mathrm{x}=1.34$, Build relationships to incur trust $\mathrm{x}=1,48$, Provide opportunities to attend professional development $\mathrm{x}=1.52$, Model good coaching behavior $\mathrm{x}=1.44$, Provide team building activities for camaraderie in the workplace $\mathrm{x}=1.46$, Provide transparency report on school funds allocations $\mathrm{x}=1.46$, Provide materials/supplies for instructions $\mathrm{x}=1.32$, Prioritize teachers' welfare among others $\mathrm{x}=1.46$.

Table 4

Significant relationship between the principal management skills and school administrative officer support.

\begin{tabular}{cccccc}
\hline X & Y & r-value & p-value & Decision & Interpretation \\
\hline $\begin{array}{c}\text { Principal } \\
\text { Management Skills }\end{array}$ & $\begin{array}{c}\text { School Administrative } \\
\text { Officer Support }\end{array}$ & $\mathbf{. 6 3 5}$ & $\mathbf{0 . 0 0 0}$ & Significant & $\begin{array}{c}\text { Moderately Positive } \\
\text { Relation }\end{array}$
\end{tabular}

Legend: $0.01-0.19=$ No relation; 0.20-0.29 = Weak Positive correlation; 0.30-0.39 = Moderate Positive Relation; 0.40-0.69 = Strong Positive Relation; 0.70-1.00 = Very Strong Positive Relation

The table showed the computed $r=0.727$, which implied as very strong positive relation while the computed p-value is 0.000 which is perfectly lessened than the alpha level of a $=0.05$ asserted as "Significant". Both computed r-value and p-value have similar findings and those findings coincides with each other. The null hypothesis of "There is no significant influence of principal management skills and school administrative officer support" is concluded as "rejected".

\section{Conclusion}

The teachers were highly satisfied on the performance of the school principal with regards to its management skills. School administrative officer support were found of very good in providing the needs of the teachers and the school. Teachers were satisfied as well in terms of professional development. The result of the findings showed that both the principal management skills and school admiration support were found of very good performance based from the teacher's satisfaction. Moreover, principal's managerial skills do relate to the school administrative support and teachers' development which pointed out that, principal's managerial skills served as a factor that provides impact to the quality of support rendered by school administrators and professional development that was considered by teachers. 


\section{Acknowledgements}

To God be the Glory, for all the strength, intellect and firmness He has given to me to finish my manuscript.

The researcher wants to give her overwhelming thanks to all people who showed their love, support and guidance in doing her study. These special people are the following to wit:

Dr. Alhadzmar A. Lantaka the research professor, for the encouragement, pieces of advice, and sharing his knowledge and expertise to finish this study. research.

The researcher's participants, for allowing their requested participation in the completion of this

Co-teachers and friends for the moral support.

Loving family, for their pieces of advice, endless love, prayers, untiring moral and financial support.

\section{References}

Anonim, Management Strategy in Education Quality Improvement (Strategi Dalam Peningkatan Mutu Pendidikan), Bandung: Alfabeta 2009.

Davis \& Werther, Personnel Management and Human Resources, McGraw-Hill: Kogakusha, 1996.

Hasibuan, S. P., Basic Management and Problem Definition, Jakarta: Earth Literacy, 2001.

https://sccounty01.co.santa-cruz.ca.us//personnel/Specs/UW5spec.html

Greenleaf, C. L., Hanson, T. L., Rosen, R., Boscardin, D. K., Herman, J., Schneider, S. A., Madden, S., \& Jones, B. (2011).

Integrating literacy and science in biology: Teaching and learning impacts of reading apprenticeship professional development. American Educational Research Journal, 48(3), 647-717. 4. Lara-Alecio, R., Tong, F., Irby, B. J., Guerrero, C., Huerta, M., \& Fan, Y. (2012).

Differential effects of three professional development models on teacher knowledge and student achievement in elementary science. Journal of Research in Science Teaching, 49(3), 333-362. 